\title{
Bioinformatic analysis revealing mitotic spindle assembly regulated NDC80 and MAD2L1 as prognostic biomarkers in non- small cell lung cancer development
}

Rong Wei ${ }^{\dagger}$, Ziyue Wang ${ }^{\dagger}$, Yaping Zhang, Bin Wang, Ningning Shen, Li E, Xin Li, Lifang Shang, Yangwei Shang, Wenpeng Yan, Xiaoqin Zhang, Wenxia Ma* and Chen Wang ${ }^{*}$ (D)

\begin{abstract}
Background: Lung cancer has been the leading cause of tumor related death, and $80 \% \sim 85 \%$ of it is non-small cell lung cancer (NSCLC). Even with the rising molecular targeted therapies, for example EGFR, ROS1 and ALK, the treatment is still challenging. The study is to identify credible responsible genes during the development of NSCLC using bioinformatic analysis, developing new prognostic biomarkers and potential gene targets to the disease.

Methods: Firstly, three genes expression profiles GSE44077, GSE18842 and GSE33532 were picked from Gene Expression Omnibus (GEO) to analyze the genes with different expression level (GDEs) between NSCLC and normal lung samples, and the cellular location, molecular function and the biology pathways the GDEs enriched in were analyzed. Then, gene function modules of GDEs were explored based on the protein-protein interaction network (PPI), and the top module which contains most genes was identified, followed by containing genes annotation and survival analysis. Moreover, multivariate cox regression analysis was performed in addition to the Kaplan meier survival to narrow down the key genes scale. Further, the clinical pathological features of the picked key genes were explored using TCGA data.
\end{abstract}

Results: Three GEO profiles shared a total of 664 GDEs, including 232 up-regulated and 432 down-regulated genes. Based on the GDEs PPI network, the top function module containing a total of 69 genes was identified, and 31 of 69 genes were mitotic cell cycle regulation related. And survival analysis of the 31 genes revealed that 17/31 genes statistical significantly related to NSCLC overall survival, including 4 spindle assembly checkpoints, namely NDC80, BUB1B, MAD2L1 and AURKA. Further, multivariate cox regression analysis identified NDC80 and MAD2L1 as independent prognostic indicators in lung adenocarcinoma (LUAD) and squamous cell carcinoma (LUSC) respectively. Interestingly, pearson correlation analysis indicated strong connection between the four genes NDC80, BUB1B, MAD2L1 and AURKA, and their clinical pathological features were addressed.

* Correspondence: 865670447@qq.com; wangchen8877322@126.com ${ }^{\dagger}$ Rong Wei and Ziyue Wang contributed equally to this work. Department of Pathology, The Second Hospital of ShanXi Medical University, No.382 WuYi Road, Tai Yuan City 030000, ShanXi Province, China

C The Author(s). 2020 Open Access This article is licensed under a Creative Commons Attribution 4.0 International License, which permits use, sharing, adaptation, distribution and reproduction in any medium or format, as long as you give appropriate credit to the original author(s) and the source, provide a link to the Creative Commons licence, and indicate if changes were made. The images or other third party material in this article are included in the article's Creative Commons licence, unless indicated otherwise in a credit line to the material. If material is not included in the article's Creative Commons licence and your intended use is not permitted by statutory regulation or exceeds the permitted use, you will need to obtain permission directly from the copyright holder. To view a copy of this licence, visit http://creativecommons.org/licenses/by/4.0/. The Creative Commons Public Domain Dedication waiver (http://creativecommons.org/publicdomain/zero/1.0/) applies to the data made available in this article, unless otherwise stated in a credit line to the data. 
(Continued from previous page)

Conclusions: Using bioinformatic analysis of GEO combined with TCGA data, we revealed two independent prognostic indicators in LUAD and LUSC respectively and analyzed their clinical features. However, more detailed experiments and clinical trials are needed to verify their drug targets role in clinical medical use.

Keywords: Non-small cell lung cancer (NSCLC), Lung adenocarcinoma (LUAD), Squamous cell carcinoma (LUSC), GEO database, TCGA data, Biomarker

\section{Background}

Lung cancer has been a common malignant tumor worldwide [1], with the morbidity only second to prostatic cancer in male and breast cancer in female [2]. As for the mortality, lung cancer has been the top killer of cancer-related death both in male and female for decades [3, 4]. The other two cancer-related death that next to lung cancer are prostatic cancer and colorectal cancer in male, as well as breast cancer and colorectal cancer in female, the four cancer types taking up $45 \%$ of the whole malignant tumor related death roll. Meanwhile within the lung cancer, $80 \% \sim 85 \%$ is non-small cell lung cancer (NSCLC), including adenocarcinoma, squamous cell carcinoma and large cell carcinoma [2].

Besides the traditional surgery, chemotherapy and radiotherapy, targeted therapy is a newly developed clinical curative method in NSCLC involving tens genes, including EGFR, ALK, ROS1, BRAF, HER2, PIK3CA, RET and so on [5]. For instance, the discovery of the frequent mutation of EGFR in NSCLC especially lung adenocarcinoma in nonsmoking female Asia patients leading to the development of generations EGFR-TKI (tyrosine kinase inhibitors) treatment, which has been showing effective results [6-8]. Additionally, the rearrangements of ALK, ROS1 and RET genes bring in the development of therapeutic TKI treatments, for instance crizotinib and lorlatinib $[9,10]$. The overall disease responsive rate is reported to be as high as $55 \%$, meanwhile the progression-free survival rate reaches $72 \%$ in NSCLC patients with ALK rearrangement $[11,12]$.

However, the currently available drug targets are lacking as opposed to the progressively developing cancer. Even with the rising molecular targeted therapies that shows promising treatment effects, the current situation for NSCLC clinical treatment is not promising. To understand more clear about the genetic information of NSCLC thus identifying potential prognostic biomarkers and new drug targeting genes is of great importance.

Recently, the development of high-throughput technologies, for instance protein chips, next generation sequencing and single cell sequencing bring in tremendous molecular data, which are publicly available, providing great chances for us to uncover novel genomic targets for therapeutic intervention [13, 14].

In the study, three cDNA expression profiles GSE44077 [15], GSE18842 [16] and GSE33532 [17] were firstly picked from Gene Expression Omnibus (GEO) based on their sample number to detect the genes with different expression level (GDEs) in NSCLC versus normal lung samples. Then, based on the protein-protein interacting (PPI) network of GDEs, GDEs function modules were analyzed and the top module containing most GDEs was picked, and all the containing genes were identified to evaluate the association with patients overall survival (OS) using KM plot online database and cox regression analysis. Moreover, the cellular component, molecular functions, signaling pathways and biological processes of the hub genes, namely the genes that were statistical significantly correlate with NSCLC OS would be analyzed, and their clinical pathological features would be evaluated using TCGA data. The results shall be useful for identifying new prognostic biomarkers and potential gene targets in clinical NSCLC treatment.

\section{Methods}

\section{Data source: three cDNA profiles from GEO online} database

From GEO online public database [18], three cDNA expression datasets GSE18842, GSE44077 and GSE33532 were picked based on the sample size (Only the profiles that contain at least 20 paired samples were considered). Within the 3 profiles, GSE18842 was based on GPL570[HG-U133_Plus_2] Affymetrix Human Genome U133 Plus 2.0 Array, containing 46 NSCLC cancer and 45 normal lung samples. And GSE44077 profile was based on GPL6244[HuGene-1_0-st] Affymetrix Human Gene 1.0 ST Array, including 55 cancer and 66 normal lung samples. And GSE33532 was based on GPL570[HG-U133_Plus_2] Affymetrix Human Genome U133 Plus 2.0 Array, covering 80 cancer and 20 normal samples.

Unearth of the GDEs in NSCLC from normal lung samples GEO2R tool [19] is provided pared with GEO data online, and in the study, it wad used to analyze the GDEs between NSCLC and normal lung samples. The criteria for GDEs identification were set as $|\log 2 \mathrm{FC}| \geq 1$ and adjusted $P$ value $<0.05$.

\section{Pathway enrichment of GDEs revealed by GO and KEGG} Gene ontology analysis (GO) is effectively used to identify characteristic biological attributes of high- 


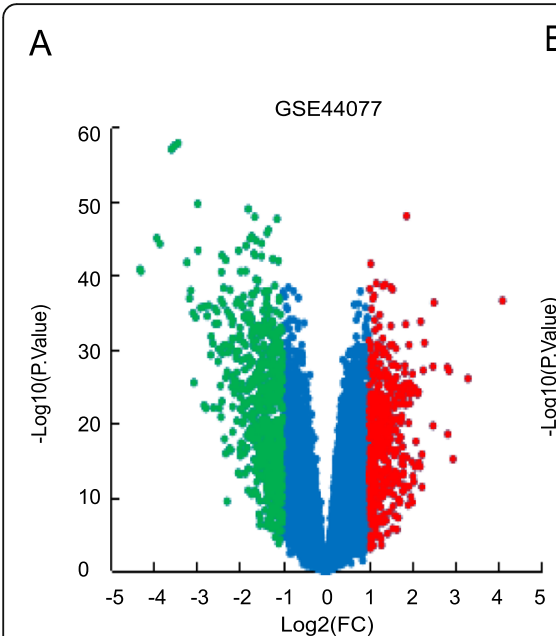

B

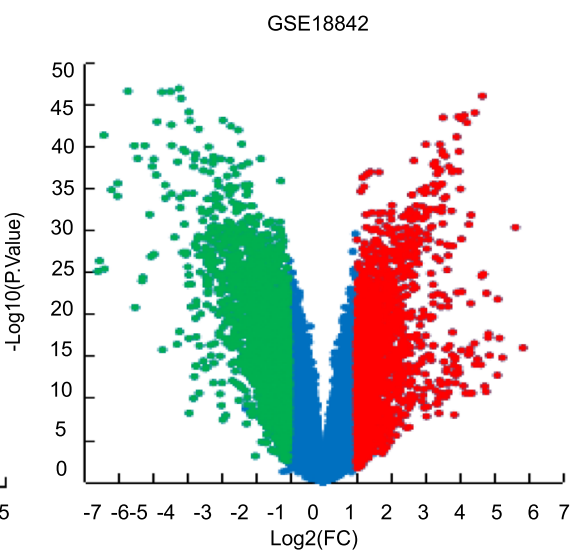

C

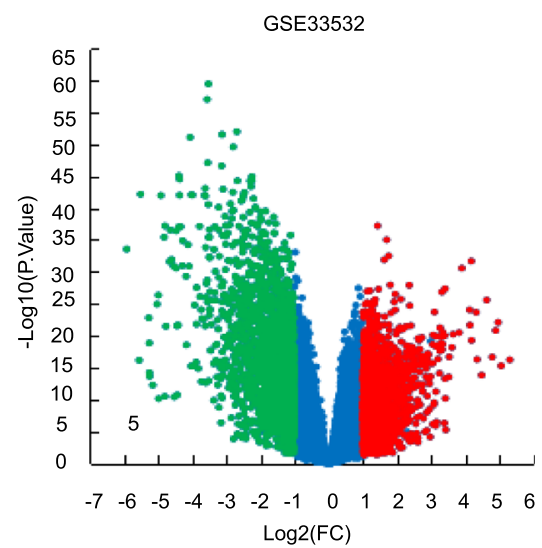

D

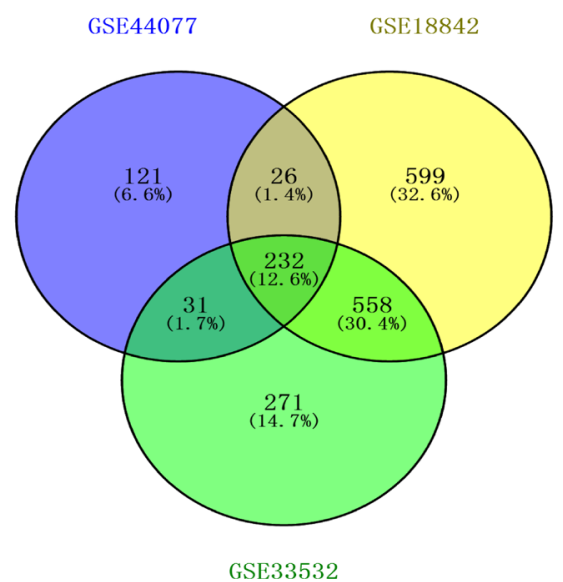

E

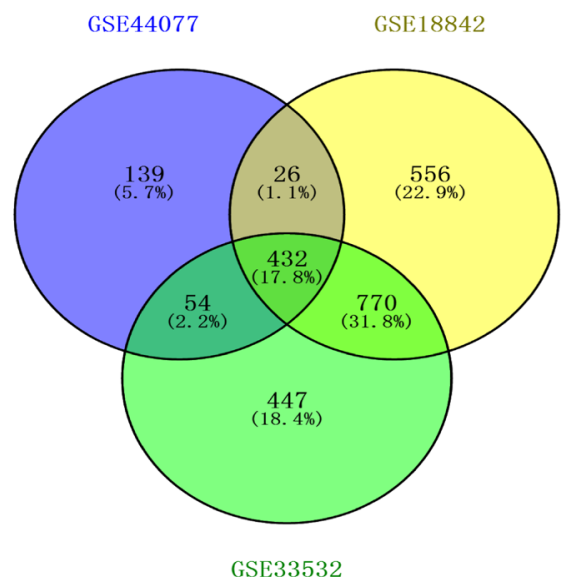

Fig. 1 The GDEs analyzed by three GEO expression profiles. Up-regulated (red-colored) and down-regulated (green-colored) GDEs in NSCLC versus normal lung tissues analyzed based on GEO profiles a GSE44077, b GSE18842 and c GSE33532 respectively. 232 up-regulated GDEs and (E) 432 down-regulated GDEs were shared in three cDNA expression profiles

throughput genetic data. Meanwhile Kyoto Encyclopedia of Genes and Genomes (KEGG) is a collection of high throughput biological information covering genomes, cells, signaling pathways and so on, it is commonly used for annotation the lists of genes and interpretation of the network of signaling pathways involved. GO and KEGG analysis were performed using FUNRICH3.1 software [20] to reveal the functions enrichment of the GDEs shared in three GEO profiles, including their cellular components, molecular functions, biological processes and the signaling pathways they mainly enriched in.

\section{Construction of the PPI network of GDEs}

STRING [21] is short for Search Tool for the Retrieval of interacting Genes, and it was used in the study to analyze the protein-protein interaction (PPI) of the GDEs uncovered by GEO2R. The analyzing criteria was set as confidence score $\geq 0.4$ and maximum interactors number $=0$.
GDEs function module analysis based on PPI network Molecular Complex Detection (MCODE) plug-in of Cytoscape3.6.0 software [22] was used to screen gene function modules based on GDEs PPI network, with the degree cut-off set as 2, node score cut off set as 0.2 , the kcore equals 2 , and max depth equals 100 . Using MCODE analysis, we identified the top gene module (gene clusters sharing similar function) containing most GDEs, and GO and KEGG were further performed to annotate the genes and explore the signaling pathways of the gene modules.

Survival analysis of module genes to identify key genes Kaplan Meier plot [23] is an openly accessed online service for analyzing univariate overall survival correlation of multiple genes in various cancers including lung cancer. In the study, Kaplan Meier plot was firstly used to analyze the OS prognosis information of all the genes in the top 


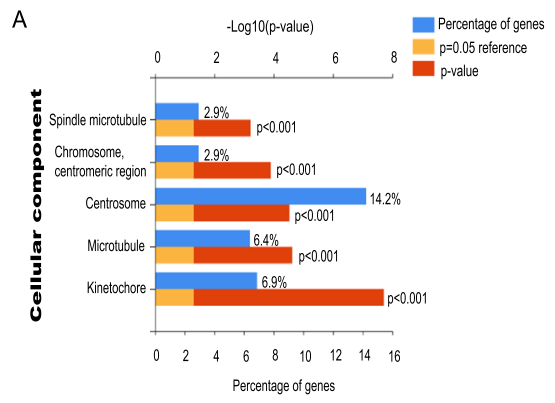

B

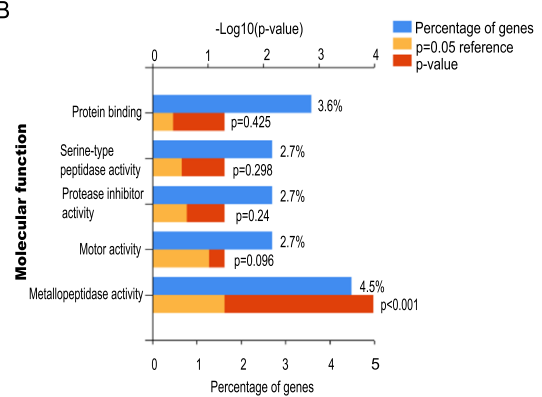

C

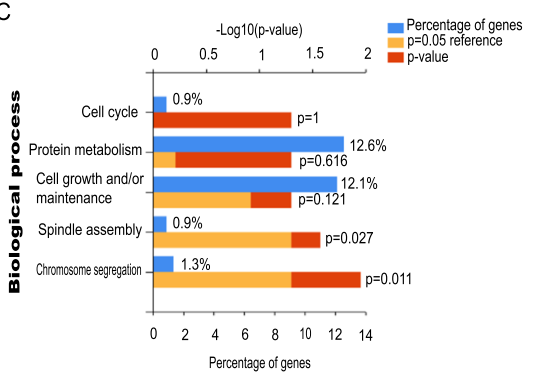

D

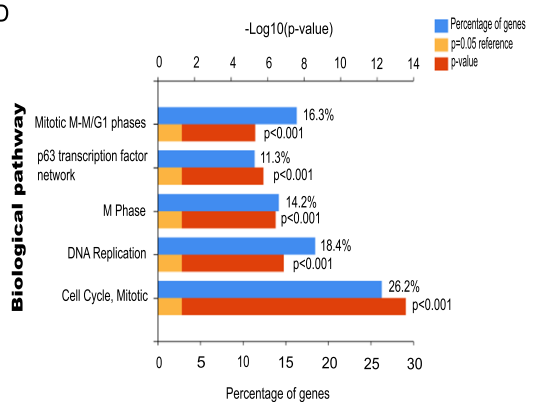

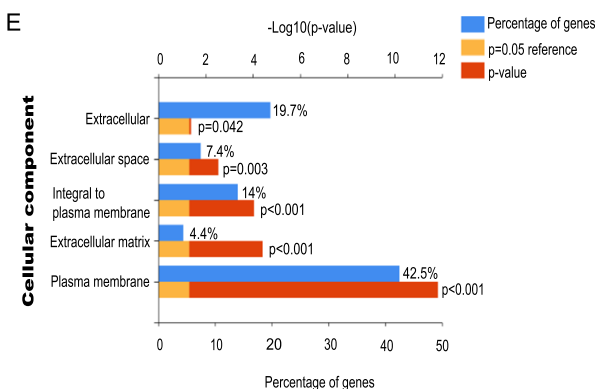

$\mathrm{F}$
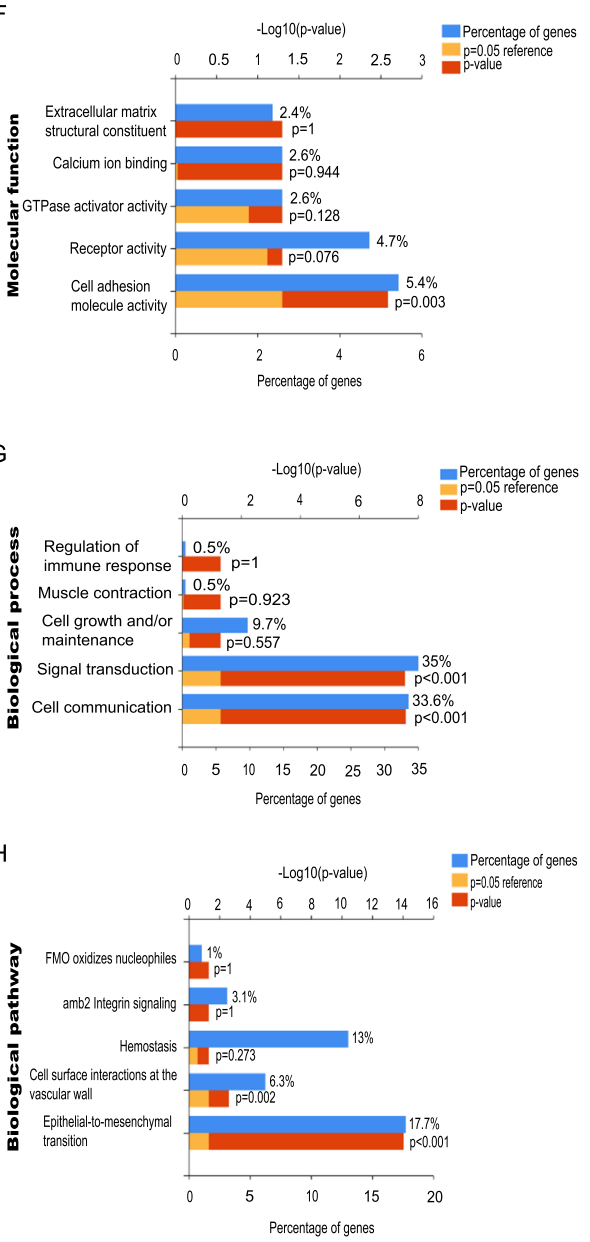

Fig. 2 GDEs function analysis by GO and KEGG in NSCLC. The cellular components, b molecular functions, c biological processes, and $\mathbf{d}$ biological pathways the up-regulated GDEs were enriched in. The cellular components, $\mathbf{f}$ molecular functions, $\mathbf{g}$ biological processes, and $\mathbf{h}$ biological pathways the down-regulated GDEs were enriched in

module to screen for the genes that have statistical significant correlation with NSCLC patients survival.

And then multivariate COX regression analysis was performed using TCGA mRNA transcription data including 223 lung adenocarcinoma and 482 lung squamous cell carcinoma, which were downloaded from TCGA database [24] to identify the independent prognostic indicators from the univariate significant gene lists. Further, the genes' association with clinical features were validated using lung adenocarcinoma and lung squamous cell carcinoma samples data provided on an online server UALCAN.

\section{Related signaling pathways and co-expression genes analysis}

GEPIA [25] is a commonly used online service for analyzing certain genes expression differences between cancer and normal tissues in various tumor types and 
A

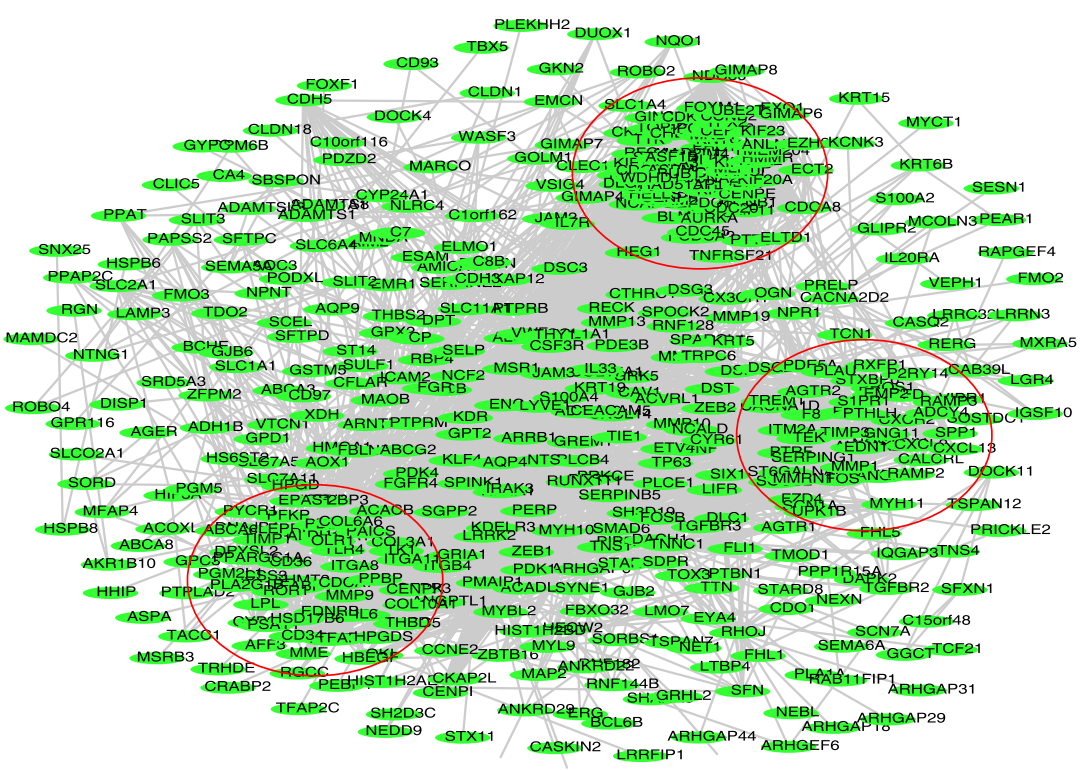

B

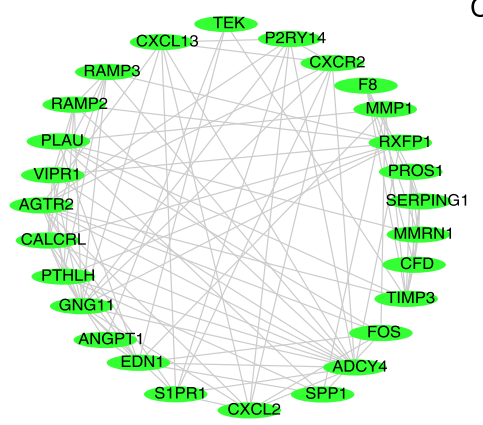

C

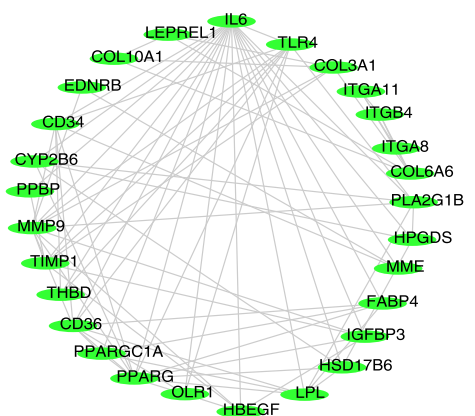

D

E
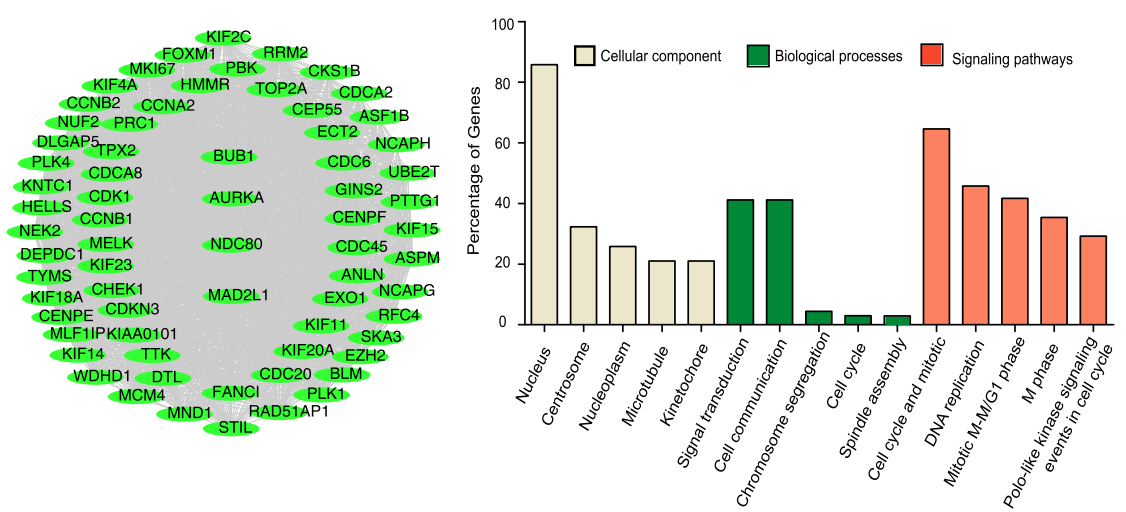

Fig. 3 GDEs gene function modules analysis based on PPI network. The PPI network of 664 GDEs, and three top gene modules analyzed based on the network, each red circle represents one gene module. $\mathbf{d}$ Three gene modules containing b 27, c 28 and $\mathbf{d} 69$ GDEs respectively. e GO and KEGG analysis reveal the basis functions including cellular components, biological processes and signaling pathways the 69 genes in top module mainly enriched in

exploring the correlation between genes. In the study, we used GEPIA to analyze key genes' (the genes that statistical significantly correlates with NSCLC OS) general expression in lung cancer comparing to normal lung samples and explore the genes that harbor similar expression with analyzed key genes.

\section{Results}

Identification of 664 GDEs shared by three GEO profiles

Three GEO cDNA profiles GSE44077, GSE18842 and GSE33532 were picked to analyze the GDEs in cancer vs. normal lung samples. And a whole of 1133, 4459 and 3775 GDEs including 691, 2505, 2351 down-regulated 
Table 1 Signaling pathways that Cluster 1 genes mainly enriched in

\begin{tabular}{|c|c|c|c|}
\hline pathways & count & $\boldsymbol{P}$ value & Related GDEs in the network \\
\hline Cell Cycle, Mitotic & 31 & $\begin{array}{l}2.76403 \mathrm{E}- \\
29\end{array}$ & $\begin{array}{l}\text { CENPE; KNTC1; KIF18A; TOP2A; MAD2L1; CCNB2; CKS1B; MCM4; CCNB1; PTTG1; NUF2; CDK1; } \\
\text { AURKA; PLK1; TYMS; CCNA2; CDC20; NDC80; BUB1; CDC6; GINS2; CDC45; PLK4; CDCA8; KIF2OA; } \\
\text { RRM2; KIF2C; RFC4; KIF23; CENPF; NEK2; }\end{array}$ \\
\hline DNA Replication & 22 & $\begin{array}{l}1.71367 \mathrm{E}- \\
18\end{array}$ & $\begin{array}{l}\text { CENPE; KNTC1; KIF18A; MAD2L1; MCM4; NUF2; CDK1; PLK1; CDC20; NDC80; BUB1; CDC6; GINS2; } \\
\text { CDC45; PLK4; CDCA8; KIF2OA; KIF2C; RFC4; KIF23; CENPF; NEK2; }\end{array}$ \\
\hline Mitotic M-M/G1 phases & 20 & $\begin{array}{l}1.48601 \mathrm{E}- \\
16\end{array}$ & $\begin{array}{l}\text { CENPE; KNTC1; KIF18A; MAD2L1; MCM4; NUF2; CDK1; PLK1; CDC20; NDC80; BUB1; CDC6; CDC45; } \\
\text { PLK4; CDCA8; KIF2OA; KIF2C; KIF23; CENPF; NEK2; }\end{array}$ \\
\hline M Phase & 17 & $\begin{array}{l}5.76137 \mathrm{E}- \\
16\end{array}$ & $\begin{array}{l}\text { CENPE; KNTC1; KIF18A; MAD2L1; NUF2; CDK1; PLK1; CDC20; NDC80; BUB1; PLK4; CDCA8; KIF20A; } \\
\text { KIF2C; KIF23; CENPF; NEK2; }\end{array}$ \\
\hline $\begin{array}{l}\text { Polo-like kinase signaling } \\
\text { events in the cell cycle }\end{array}$ & 14 & $\begin{array}{l}2.77681 \mathrm{E}- \\
14\end{array}$ & $\begin{array}{l}\text { CENPE; CCNB1; CDK1; AURKA; TPX2; ECT2; PLK1; PRC1; CDC20; NDC80; BUB1; PLK4; DLGAP5; } \\
\text { KIF20A; }\end{array}$ \\
\hline PLK1 signaling events & 13 & $\begin{array}{l}3.83583 \mathrm{E}- \\
13\end{array}$ & CENPE; CCNB1; CDK1; AURKA; TPX2; ECT2; PLK1; PRC1; CDC20; NDC80; BUB1; DLGAP5; KIF20A; \\
\hline Mitotic Prometaphase & 12 & $\begin{array}{l}5.11023 \mathrm{E}- \\
12\end{array}$ & CENPE; KNTC1; KIF18A; MAD2L1; NUF2; PLK1; CDC20; NDC80; BUB1; CDCA8; KIF2C; CENPF; \\
\hline Cell Cycle Checkpoints & 11 & $\begin{array}{l}1.32039 \mathrm{E}- \\
08\end{array}$ & MAD2L1; CCNB2; MCM4; NDC80; CCNB1; CDK1; CDC20; CDC6; CDC45; RFC4; CHEK1; \\
\hline Signaling by Aurora kinases & 11 & $\begin{array}{l}1.04137 \mathrm{E}- \\
10\end{array}$ & NCAPH; NCAPG; AURKA; TPX2; NDC80; BUB1; CDCA8; DLGAP5; KIF20A; KIF2C; KIF23; \\
\hline
\end{tabular}

Only pathways containing over 10 GDEs were listed

and 442, 1954, 1424 up-regulated genes were identified in GSE44077 (Fig. 1a), GSE18842 (Fig. 1b) and GSE33532 (Fig. 1c) respectively. Additionally, 432 downregulated and 232 up-regulated GDEs were shared among the three GEO profiles showed by Venn diagram performance (Fig. 1d, e).

\section{Pathway enrichment analysis of shared GDEs by GO and KEGG}

To further understand the pathways 664 GDEs were mainly enriched in, GO and KEGG analysis were conducted. Interestingly, GO analysis showed that the cell components of 232 up-regulated GDEs were enriched in centrosome, microtubule and kinetochore (Fig. 2a), and the molecular function were focused on metallopeptidase activity (Fig. 2b). The biological process were mostly enriched in cell growth and maintenance, spindle assembly and chromosome segregation (Fig. 2c). Moreover, KEGG/biological pathway analysis showed the upregulated GDEs were mostly involved in cell mitotic and DNA replication (Fig. 2d). Three of the four aspects including genes cell component, signaling pathways and biological process suggested the orientation of cell cycle mitotic process, indicating the potential value of cell division process in cancer targeting treatment.

Meanwhile, as for the 432 down regulated GDEs, the cell components were primary focused on cellular plasma membrane (Fig. 2e), the molecular function were enriched in receptor activity and cell adhesion molecular activity (Fig. 2f), and the biological process were mainly enriched in signal transduction and cell communication (Fig. 2g). Additionally, KEGG/biological pathway analysis showed the down-regulated GDEs were mostly participated in hemostasis, cell surface interaction at vascular walls and Epithelial to Mesenchymal transition (EMT) (Fig. 2h).

\section{Function module analysis based on PPI network}

To identify the potential responsible genes in NSCLC development, the PPI network of 664 GDEs was constructed with STRING, and the function modules of the GDEs were analyzed. Based on the PPI, top three gene modules were identified containing 69, 27 and 28 genes respectively (Fig. 3a), and these three modules were named as Gene Cluster1 (Fig. 3d), 2 (Fig. 3b) and 3 (Fig. 3c) accordingly.

GO and KEGG result revealed that most of the Cluster 1 genes were enriched in the cell cycle (31/69), DNA replication (22/69) and Mitotic M-M/G1 (20/69) related signaling (Fig. 3e). All the signaling that Cluster1 genes enriched in were sorted in descending order based on the gene counts and FDR value (Table 1). We primarily focused on the top cell cycle regulation related module which matches most GDEs in the network, and we further perform survival analysis on all the 31 genes.

\section{Survival analysis of cluster 1 module genes}

Univariate Kaplan Meier plot overall survival analysis of 31 cell cycle regulation genes in Gene Cluster 1 showed that 17 out of 31 genes statistical significantly correlates with patients overall survival, including 4 spindle assembly checkpoints BUB1 (Fig. 4a), NDC80 (Fig. 4c), MAD2L1 (Fig. 4e), and AURKA (Fig. 4g). And GEPIA was then used to validate genes' gaped 
A

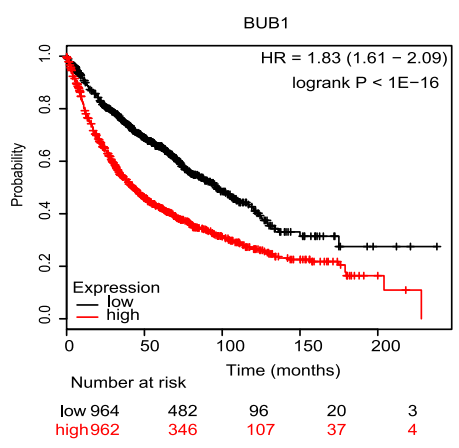

C

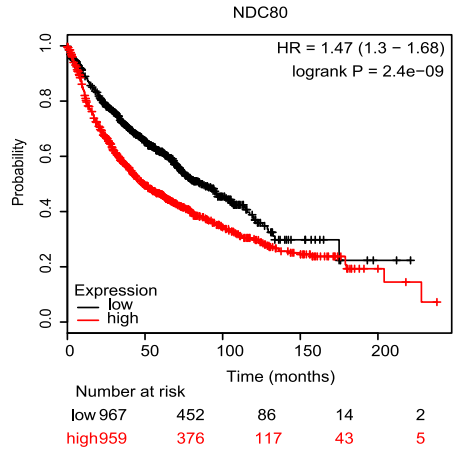

E

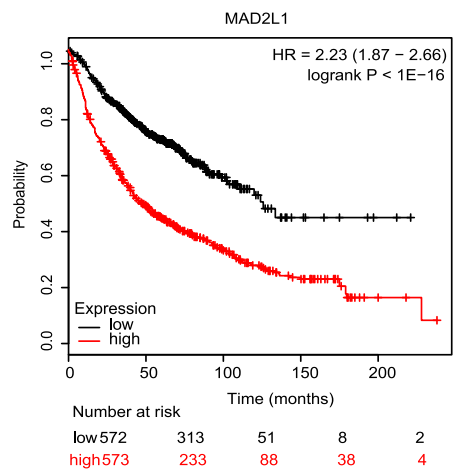

G

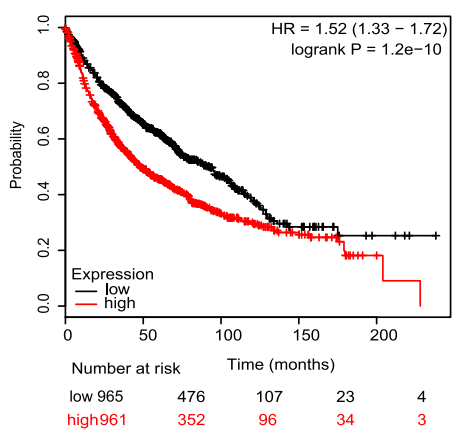

B

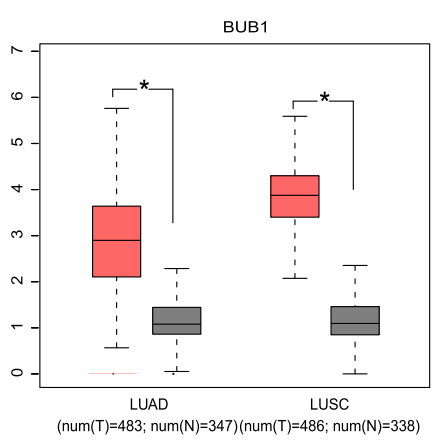

D

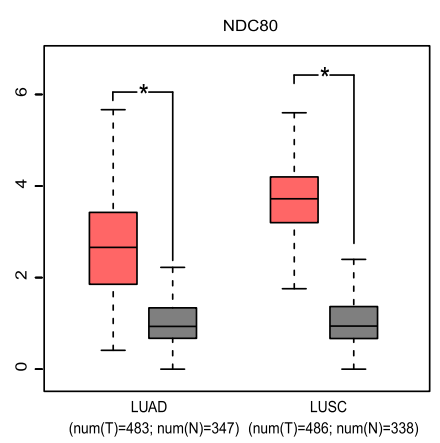

F

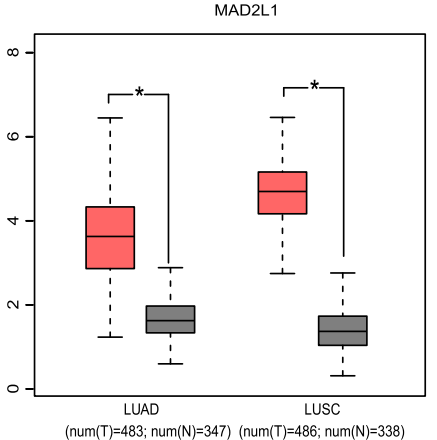

AURKA

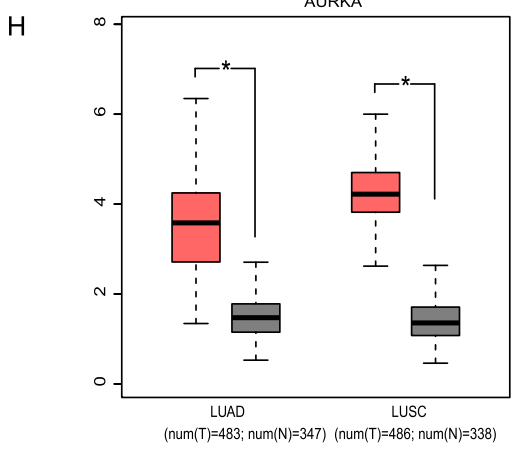

Fig. 4 Os prognosis and expression information of 4 spindle assembly checkpoints genes. Overall survival value of a BUB1, c NDC80, e MAD2L1 and $\mathbf{g}$ AURKA in NSCLC; Expression level of $\mathbf{b}$ BUB1, $\mathbf{d}$ NDC80, $\mathbf{f}$ MAD2L1 and $\mathbf{h}$ AURKA in NSCLC cancer versus normal lung tissues, including adenocarcinoma (left column) squamous cancer (right column). ${ }^{*} P<0.05$

expression in NSCLC versus normal lung samples, and the results showed the gain of expression of all four genes in cancer comparing to normal samples (Fig. 4b, d, f, h).
Further, multivariate cox regression analysis showed that patients age, p-stage, M status and NDC80 expression work as independent prognostic indicators in adenocarcinoma (Table 2), meanwhile, $\mathrm{T}$ stage, $\mathrm{M}$ 
Table 2 Multivariate cox regression analysis on LUAD overall survival

\begin{tabular}{llll}
\hline Variables & \multicolumn{3}{l}{ Lung adenocarcinoma } \\
\cline { 2 - 4 } & Hazard ratio $95 \% \mathrm{Cl}$ & $P$ value \\
\hline $\begin{array}{l}\text { Age } \\
\quad<60 \text { years vs } \geq 60 \text { years }\end{array}$ & 1.034 & $1.006 \sim 1.064$ & 0.018 \\
$\begin{array}{l}\text { Stage } \\
\quad \text { I vs II vs III vs IV }\end{array}$ & 1.554 & $1.213 \sim 1.99$ & 0.001 \\
M & & & \\
$\quad$ M $_{0}$ vs M & 2.321 & $1.172 \sim 4.069$ & 0.032 \\
NDC80 expression & & & \\
$\quad<$ median vs > median & 2.480 & $1.375 \sim 4.472$ & 0.003 \\
\hline
\end{tabular}

status and MAD2L1 expression work as an independent indicators in squamous cell carcinoma (Table 3 ).

\section{NDC80 and MAD2L1 association with NSCLC clinical features}

To explore the clinical association between NDC80 and MAD2L1 expression with LUAD and LUSC clinical features, we used two methods. Firstly, the clinical information of 482 lung squamous cell carcinoma (Detailed in Table S1) and 223 adenocarcinoma cases (Table S2) were downloaded from TCGA data (same information being used for COX regression analysis), and the results showed that NDC80 expression statistical significantly associates with LUAD patients age, smoking, and stage in adenocarcinoma, the gene tends to express higher in younger $(<60$ years), smoker and higher stage patients (Table 4). And MAD2L1 expression statistical significantly associates with LUSC lympho node and distant metastasis, the expression was higher in patients with lympho node metastasis but no distant metastasis (Table 5).

Secondly, an online analysis service Ualcan which is also based on TCGA data was also used for data exploration (Fig. 5a-n), the result also revealed that NDC80 expresses higher in smoker than non smokers and the expression increases as the smoking years lasting longer (Fig. 5d), and NDC80 tends to be higher in cases with lympho node

Table 3 Multivariate cox regression analysis on LUSC overall survival

\begin{tabular}{llll}
\hline Variables & \multicolumn{3}{l}{ Lung squamous cell carcinoma } \\
\cline { 2 - 4 } & Hazard ratio & $95 \% \mathrm{Cl}$ & $P$ value \\
\hline T & 1.305 & $1.085 \sim 1.569$ & 0.005 \\
T1 vs T2 vs T3 vs T4 & & & \\
M & 1.701 & $1.172 \sim 2.469$ & 0.005 \\
$\quad$ Mo vs M & & & \\
MAD2L1 expression & & $0.567 \sim 0.999$ & 0.045 \\
\hline
\end{tabular}

Table 4 The association between NDC80 and LUAD clinical pathological features

\begin{tabular}{|c|c|c|c|}
\hline \multirow[t]{2}{*}{ parameters } & \multicolumn{2}{|l|}{ NDC80 } & \multirow[t]{2}{*}{$P$ value } \\
\hline & - & + & \\
\hline Gender & & & $P=0.209$ \\
\hline male & $45(45.9 \%)$ & $53(54.1 \%)$ & \\
\hline female & $68(54.4 \%)$ & $57(45.6 \%)$ & \\
\hline Age & & & $P=0.027$ \\
\hline$<60$ years old & $24(39.3 \%)$ & $37(60.7 \%)$ & \\
\hline$\geq 60$ years old & $82(56.2 \%)$ & $64(43.8 \%)$ & \\
\hline Smoke & & & $P=0.002$ \\
\hline no & $23(65.7 \%)$ & $12(34.3 \%)$ & \\
\hline Current smoker & $15(32.6 \%)$ & $31(67.4 \%)$ & \\
\hline Smoker $<15$ years & $31(44.9 \%)$ & $38(55.1 \%)$ & \\
\hline Smoker $\geq 15$ years & $39(59.1 \%)$ & $27(40.9 \%)$ & \\
\hline Stage & & & $P=0.032$ \\
\hline I & $66(57.4 \%)$ & $49(42.6 \%)$ & \\
\hline$\|$ & $23(48.9 \%)$ & $24(51.1 \%)$ & \\
\hline III & $15(31.9 \%)$ & $32(68.2 \%)$ & \\
\hline IV & $5(55.6 \%)$ & $4(44.4 \%)$ & \\
\hline $\mathrm{T}$ & & & $P=0.199$ \\
\hline I & $37(61.7 \%)$ & $23(38.3 \%)$ & \\
\hline$\|$ & $63(47.7 \%)$ & $68(52.3 \%)$ & \\
\hline III & $7(41.2 \%)$ & $10(58.8 \%)$ & \\
\hline IV & $6(40.0 \%)$ & $9(60.0 \%)$ & \\
\hline N & & & $P=0.053$ \\
\hline- & $69(56.6 \%)$ & $53(43.4 \%)$ & \\
\hline+ & $44(43.6 \%)$ & $57(56.4 \%)$ & \\
\hline M & & & $P=0.497$ \\
\hline- & 81 (50.9\%) & $78(49.1 \%)$ & \\
\hline+ & $27(45.8 \%)$ & 31 (54.2\%) & \\
\hline
\end{tabular}

netastasis (Fig. 5g). Interestingly, bigger sample number also yields the discovery that both NDC80 (Fig. 5c) and MAD2LI (Fig. 5j) express higher in male than female patients, hypothetically, the gender association might be related to the fact that most smokers were man rather than woman.

\section{NDC80 and MAD2L1 centered signaling pathways}

The expression profile of NDC80 and MAD2L1 was analyzed in various tumors using GEPIA and we discovered that both NDC80 and MAD2L1 were broadspectrum up-regulated in multiple human tumors including lung adenocarcinoma and lung squamous cell carcinoma (Fig. 6a, f).

To understand the potential functions of NDC80 and MAD2L1, we performed GO and KEGG to analyze the biological processes the genes mainly participate in and the signaling pathways they involve. The result revealed 
Table 5 The association between MAD2L1 and LUSC clinical pathological features

\begin{tabular}{|c|c|c|c|}
\hline \multirow[t]{2}{*}{ parameters } & \multicolumn{2}{|l|}{ MAD2L1 } & \multirow[t]{2}{*}{$P$ value } \\
\hline & - & + & \\
\hline Gender & & & $P=0.097$ \\
\hline male & $170(47.8 \%)$ & $186(52.2 \%)$ & \\
\hline female & $71(56.3 \%)$ & $55(43.7 \%)$ & \\
\hline Age & & & $P=0.100$ \\
\hline$<60$ years old & $44(42.7 \%)$ & $59(57.3 \%)$ & \\
\hline$\geq 60$ years old & 192 (51.9\%) & $178(48.1 \%)$ & \\
\hline Smoke & & & $P=0.973$ \\
\hline no & $131(50.6 \%)$ & $128(49.4 \%)$ & \\
\hline Smoker < 15 years & $28(50.0 \%)$ & $28(50.0 \%)$ & \\
\hline Smoker $\geq 15$ years & $82(49.4 \%)$ & $84(50.6 \%)$ & \\
\hline Stage & & & $P=0.062$ \\
\hline I & $132(56.2 \%)$ & $103(43.8 \%)$ & \\
\hline$\|$ & $70(44.6 \%)$ & $87(55.4 \%)$ & \\
\hline III & 35 (42.7\%) & $47(57.3 \%)$ & \\
\hline IV & $4(57.1 \%)$ & $3(42.9 \%)$ & \\
\hline T & & & $P=0.314$ \\
\hline I & $60(56.1 \%)$ & $47(43.9 \%)$ & \\
\hline$\|$ & $131(46.5 \%)$ & 151 (53.5\%) & \\
\hline III & $38(54.3 \%)$ & $32(45.7 \%)$ & \\
\hline IV & $12(52.2 \%)$ & $11(47.8 \%)$ & \\
\hline $\mathrm{N}$ & & & $P=0.001$ \\
\hline- & $171(55.9 \%)$ & $135(44.1 \%)$ & \\
\hline+ & $70(39.8 \%)$ & $106(60.2 \%)$ & \\
\hline M & & & $P=0.036$ \\
\hline- & $188(48.0 \%)$ & $204(52.0 \%)$ & \\
\hline+ & $52(60.5 \%)$ & $34(39.5 \%)$ & \\
\hline
\end{tabular}

an really interesting fact that even in different sub types of lung cancer (LUAD and LUSC), NDC80 and MAD2L1 shared biological functions. Both NDC80 (Table 6) and MAD2L1 (Table 7) were primarily focused on mitotic cell cycle regulation related processes, for instance cell division, chromosome segregation and spindle assembly regulating signaling.

Moreover, NDC80 and MAD2L1 centered PPI network showed a similar result that the genes NDC80 (Fig. 6b) and MAD2L1 (Fig. 6g) related were both cell cycle regulation involved including BUB1B and AURKA. GEPIA analysis confirmed the correlation between NDC80 and MAD2L1, BUB1B, AURKA in both LUAD (Fig. 6c-e) and LUSC (Fig. 6h-j).

Considering that great proportion of current chemotherapy drugs are developed based on their association with cell mitosis cycle, the correlation between NDC80, MAD2L1 and cell division process indicate the potential value these genes working as two other chemotherapy drug targets. However, more experiments and clinical trials will be needed to validate the hypothesis.

\section{Discussion}

Lung cancer has been the top killer among various malignant tumors worldwide, with the morbidity only second to prostatic cancer in male and breast cancer in female. Within the lung cancer, $80 \% \sim 85 \%$ is NSCLC. Even with the rising of molecular targeted therapies, including EGFR, BRAF, C-MET, ALK, ROS1, RET and so on, the outcome of the disease is still not promising. The study is conducted to explore new potential biomarkers and gene targets by bioinformatic analyzing.

From the online open-access GEO databases, three cDNA expression profiles GSE44077, GSE18842 and GSE33532 containing a total of of 181 NSCLC cancer and 131 normal lung samples were picked, and the GDEs between cancer versus normal tissues were then analyzed, and we discoved that 664 genes were differently expressed in three cDNA profiles, including 232 up-regulated and 432 down-regulated genes.

Then, we performed GO and KEGG analysis to annotate the 664 GDEs, and the results showed that the cell component that the 432 down-regulated genes mainly enriched in were plasma membrane, the biological processes the genes focused on were signal transduction and cell communication. The molecular functions that genes enriched in were receptor activity and cell adhesion molecular activity. Meanwhile, the biological pathways that down-regulated GDEs mostly enriched in were hemostasis and cell surface interaction at vascular walls.

To provoke our interests, three out of the four aspects the 232 up-regulated GDEs, including their cell growth and maintenance, spindle assembly and chromosome segregation enriched biological process, centrosome, microtubule and kinetochore centralized cell components and cell cycle/mitotic and DNA replication focused biological pathways point to the orientation of cell cycle mitotic process.

On top of it, the function modules analysis of GDEs revealed that most of the top module genes were also cell cycle regulation related. Overall survival analysis showed $17 / 31$ of the top module genes statistical significantly correlate with NSCLC OS including four spindle assemble checkpoints NDC80, BUB1B, MAD2L1 and AURKA. Multivariate COX regression analysis supported NDC80 and MAD2L1 working as independent prognostic indicators in LUAD and LUSC respectively. Clinical features association analysis showed that NDC80 tends to expresses higher in younger ( $<60$ years) LUAD patients who smoke. And MAD2L1 usually expresses higher in LUSC patients with lympho node metastasis. Moreover, NDC80 and MAD2L1 centered 


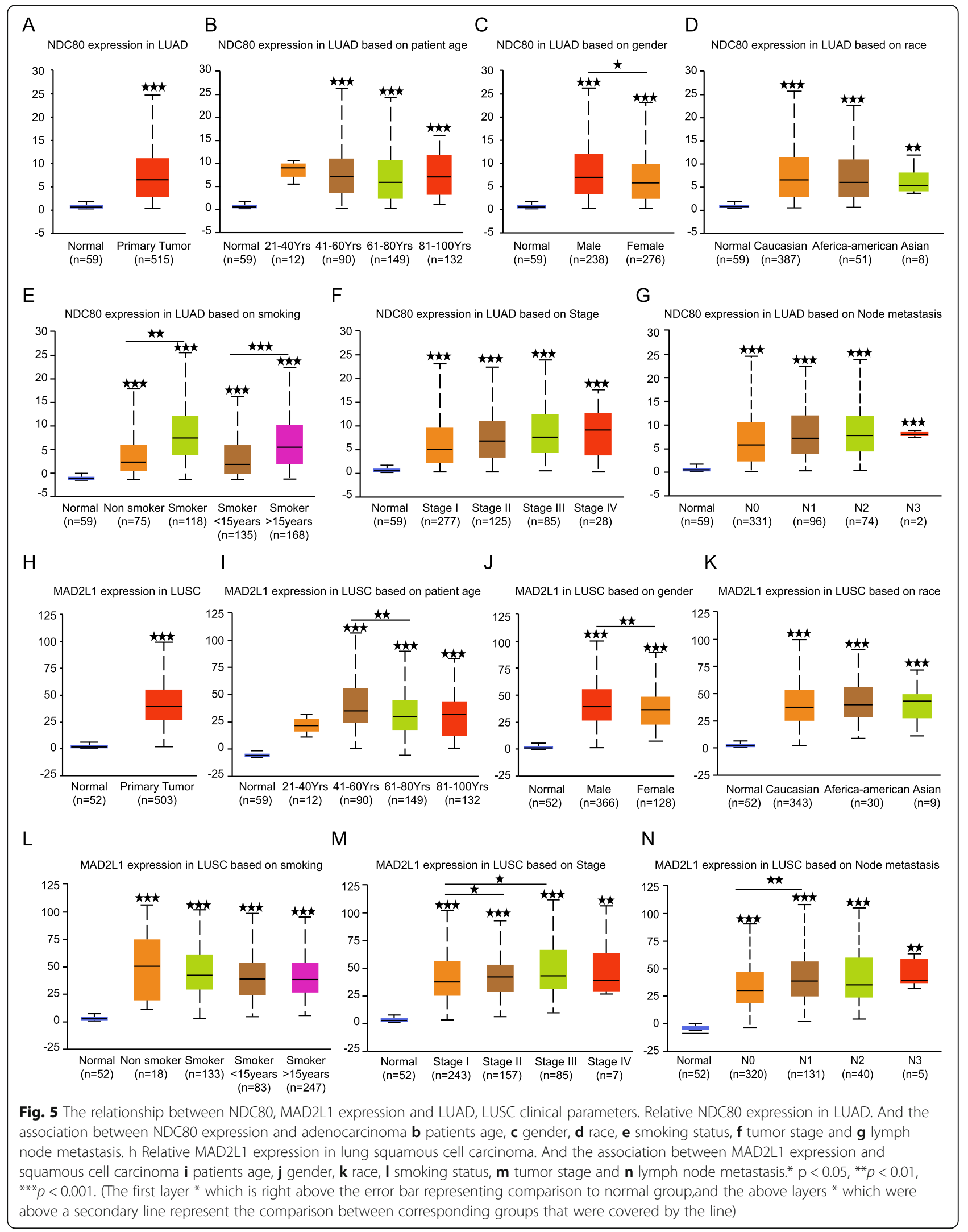




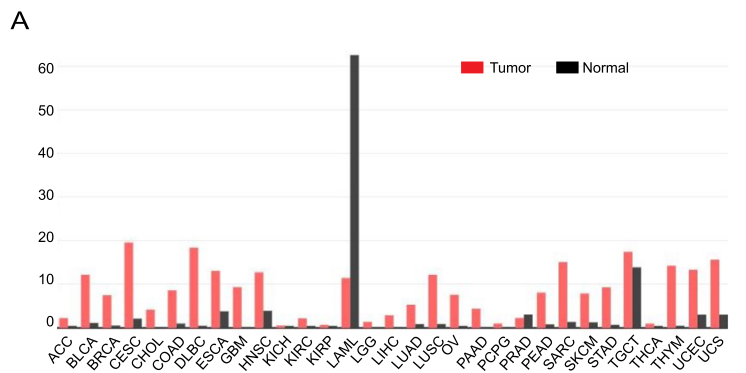

C

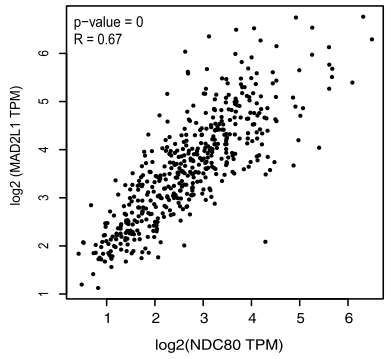

$\mathrm{F}$

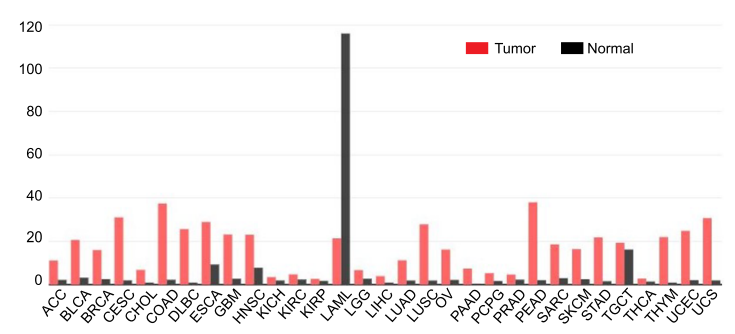

$\mathrm{H}$

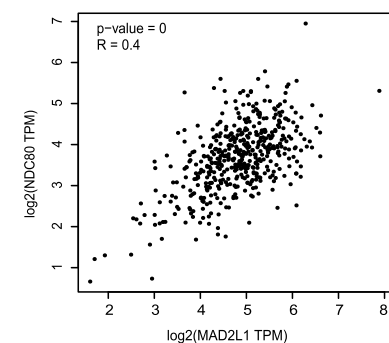

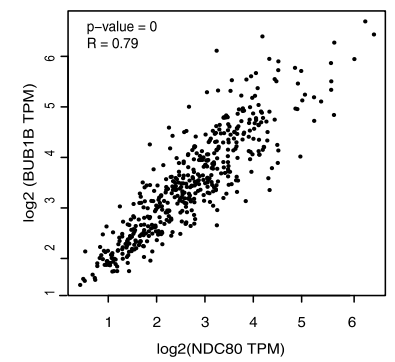

G
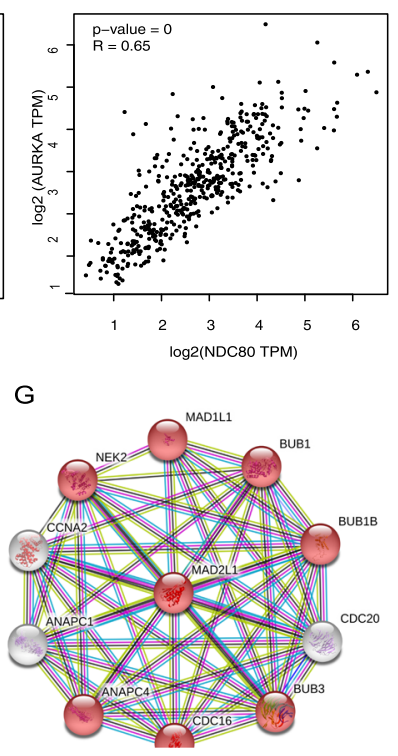

$\mathrm{J}$

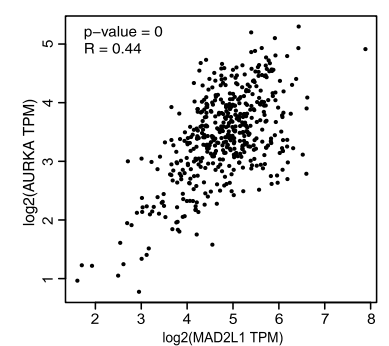

Fig. 6 NDC80 and MAD2L1 related signaling analysis. Expression of NDC80 in various human cancers revealed by GEPIA. NDC80 centered PPI network representing the genes most related to NDC80. e Correlation between NDC80 and c MAD2L1, d BUB1B and e AURKA in LUAD revealed by GEPIA (R=0.67, 0.79, 0.65 respectively). $\mathbf{f}$ Expression of MAD2L1 in various human cancers revealed by GEPIA. $\mathbf{g}$ MAD2L1 centered PPI network representing the genes most related to MAD2L1. $\mathbf{h}$-j Correlation between MAD2L1 and $\mathbf{h}$ NDC80, $\mathbf{i}$ BUB1B and $\mathbf{j} A U R K A$ in LUSC revealed by GEPIA ( $R=0.40,0.46,0.44$ respectively)

biological processes and signaling pathways also highly support their involvement in the cell cycle regulation.

In fact, cell cycle regulators have been strongly implicated in the progression of various tumors [26, 27], and disruption of cell cycle pathways including spindle assembly has been one of the main focus of current development of chemotherapy drugs [28-30], for instance taxol and colchicine, which disrupts the microtubule polymerization dynamics, leading to inordinate spindle function and eventually cell death [31-34].

The over expression of multiple spindle checkpoints is revealing another potential microtubule-targeted strategy, the direct attack to spindle assemble checkpoint function, to arrest the cell cycle process in the prometaphase, thus leading to mitotic catastrophe and eventually cancer cell death. 
Table 6 Go analysis revealing biological processes centered on NDC80

\begin{tabular}{|c|c|c|c|c|}
\hline Description & $\begin{array}{l}\text { Gene } \\
\text { counts }\end{array}$ & $\begin{array}{l}\text { Background gene } \\
\text { counts }\end{array}$ & FDR & Matching proteins in the network \\
\hline Cell division & 11 & 483 & $\begin{array}{l}7.33 \mathrm{E}- \\
16\end{array}$ & $\begin{array}{l}\text { AURKB,BUB1,BUB1B,CASC5,NUF2,CENPE,MAD2L1,NDC80,SPC24,SPC25, } \\
\text { ZWINT }\end{array}$ \\
\hline Chromosome segregation & 10 & 253 & $\begin{array}{l}7.33 \mathrm{E}- \\
16\end{array}$ & $\begin{array}{l}\text { AURKB,BUB1,BUB1B,CASC5,CENPE, MAD2L1,NDC80,NUF2,SPC25, } \\
\text { ZWINT }\end{array}$ \\
\hline Sister chromatid segregation & 7 & 123 & $\begin{array}{l}1.31 \mathrm{E}- \\
11\end{array}$ & AURKB,BUB1,BUB1B,CENPE,MAD2L1, NDC80,ZWINT \\
\hline $\begin{array}{l}\text { Spindle attachment to } \\
\text { kinetochore }\end{array}$ & 4 & 20 & $\begin{array}{l}1.32 \mathrm{E}- \\
08\end{array}$ & AURKB,CASC5,CENPE,NDC80 \\
\hline Spindle checkpoint & 4 & 23 & $\begin{array}{l}2.07 \mathrm{E}- \\
08\end{array}$ & AURKB,BUB1,BUB1B,MAD2L1 \\
\hline
\end{tabular}

NDC80, which is short for nuclear division cycle 80, is one of the proteins of outer kinetochore. It forms a heterotetramer complex with proteins SPC24, SPC25 and NUF2, and the complex has been known to involve in spindle assembly checkpoint signaling, detecting the unaligned chromosomes to assure the correct segregation of chromosomes. Aberrant expression of NDC80 has been reported in several other tumors [35-39], for instance osteosarcoma, hepatocellulcar carcinoma, colorectal cancer and breast cancer, indicating its potential as a newly bio target.

MAD2L1, short for mitosis arrest-deficient 2 like 1 protein, is also functioning as a spindle assembly checkpoint that assures the properly alignment of chromosomes at the metaphase plate during cell division. Despite the barely known signaling pathways it participated in, MAD2L1 is shown to interact with CDC20 and BUB1B [40, 41], and correlate with aberrant development of salivary duct carcinoma [42].

BUB1, which is encoded by BUB1B, has been known as a checkpoint for proper chromosome segregation, the abnormal expression of BUB1 has been reported to associate with poor survival and metastasis in various tumors including colorectal cancer, gastric cancer, bladder cancer, hepatocellular carcinoma and so on [35, 43-45]. In the study, using bioinformatic analysis, we confirmed the correlation between over expression of BUB1B and poor survival of NSCLC patients.

Aurora kinase A (AURKA) belongs on a family of serine/threonine kinases containing other two family members aurora kinase $\mathrm{B}$ and kinase $\mathrm{C}$. The family members are known to have highly conserved genetic domains and shown to play vital roles in mitosis. As a serine/threonine kinases, AURKA activity peaks during the G2/M phase transition phase in the cell cycle, and associated with the regulation of spindle stability. Aurora A dysregulation has been associated with high occurrence of various cancers, for example breast, prostate, bladder, colorectal, gastric, ovarian, esophagus and pancreatic cancers. High expression of AURKA commonly correlates with advanced development and poor prognosis of cancers [46-48]. Osimertinib and rociletinib, two anti-cancer drugs for lung cancer, work by shutting off mutant EGFR [49], which initially kills cancerous tumors, but the tumors rewire and activate Aurora kinase A, becoming cancerous growths again $[50,51]$. A recent study shows that to target both EGFR and Aurora shall prevents return of drug resistant tumors [52-54].

Further clinical validation of the tumor promoter and worse prognosis predictor function of $\mathrm{NDC} 80$ and MAD2L1 in local LUAD and LUSC patients as well as the genes' relation with BUB1B and AURKA is on our

Table 7 Go analysis revealing biological processes centered on MAD2L1

\begin{tabular}{|c|c|c|c|c|}
\hline Description & $\begin{array}{l}\text { Gene } \\
\text { counts }\end{array}$ & $\begin{array}{l}\text { Background gene } \\
\text { counts }\end{array}$ & FDR & Matching proteins in the network \\
\hline Cell division & 10 & 483 & $\begin{array}{l}1.09 \mathrm{E}- \\
15\end{array}$ & $\begin{array}{l}\text { ANAPC1,ANAPC4,BUB1,BUB1B,BUB3, CDC16,CDC20, } \\
\text { MAD1L1,MAD2L1,NEK2 }\end{array}$ \\
\hline Nuclear division regulation & 9 & 184 & $\begin{array}{l}9.05 E- \\
15\end{array}$ & $\begin{array}{l}\text { ANAPC4,BUB1,NEK2,BUB1B,BUB3, CDC16,CDC20,MAD1L1, } \\
\text { MAD2L1 }\end{array}$ \\
\hline Chromosome organization & 8 & 999 & $\begin{array}{l}6.17 \mathrm{E}- \\
08\end{array}$ & BUB1,BUB1B,BUB3,CCNA2,CDC20, MAD1L1,MAD2L1,NEK2 \\
\hline $\begin{array}{l}\text { anaphase-promoting complex-dependent cata- } \\
\text { bolic process }\end{array}$ & 7 & 35 & $\begin{array}{l}9.05 E- \\
15\end{array}$ & ANAPC1,ANAPC4,BUB1B,BUB3,CDC16,CDC20,MAD2L1 \\
\hline Mitotic spindle assembly checkpoint & 5 & 21 & $\begin{array}{l}4.46 \mathrm{E}- \\
11\end{array}$ & BUB1,BUB1B,BUB3,MAD1L1,MAD2L1 \\
\hline
\end{tabular}


way. More experimental investigations are needed to understand the detailed molecular signaling mechanism behind the cell cycle related genes regulation on NSCLC development.

\section{Conclusion}

In conclusion, 664 GDEs between NSCLC and normal lung tissues were explored using bioinformatic analysis, and the cellular components, molecular functions, biological processes and the signaling they mainly enriched in were also revealed. Two spindle assembly checkpoints NDC80 and MAD2L1 were showed to correlate with LUAD and LUSC OS respectively. These bioinformation shall provide clues for the further unearth of new biomarkers and potential bio-targets in NSCLC.

\section{Supplementary information}

Supplementary information accompanies this paper at https://doi.org/10. 1186/s12920-020-00762-5.

Additional file 1. Supplementary Table 1 The TCGA patients barcode

for 482 LUSC samples.

Additional file 2. Supplementary Table 2 The TCGA patients barcode for 223 LUAD patients samples.

\section{Abbreviations}

NSCLC: Non-Small Cell Lung Cancer; LUAD: Lung adenocarcinoma; LUSC: Lung squamous cell carcinoma; GEO: Gene Expression Omnibus; GDEs: Genes with different expression level; GO: Gene ontology; OS: Overall survival rate; KEGG: Kyoto Encyclopedia of Gene and Genome; PPI: Proteinprotein interaction network; MCODE: Molecular Complex Detection; STRI NG: Search Tool for Retrieval of interacting Genes; EMT: Epithelial to Mesenchymal transition

\section{Acknowledgements}

We sincerely appreciate the researchers for providing their GEO and TCGA databases information online, we are truly honored to acknowledge their contributions.

\section{Authors' contributions}

RW, ZW designed the study and drafted the manuscript, contributed equally to the whole study. YZ, BW and NS worked on the data collectiong and acquision, and they also led the data analysis in the whole study. $L E, X L$ and LS performed the data interpretation and assisted the study design, YS, WY and $X Z$ assisted manuscript revising and figures organizing. As the corresponding author, WM and CW were responsible for critical revision of the manuscript and have full access to all data generated from the project. All listed authors read and approved the final version of manuscript for publication.

\section{Funding}

All the genetic analyzing and data processing work was supported by the grant of Health Commission of ShanXi Province in China to Chen Wang (NO.2018050).

\section{Availability of data and materials}

In the study, different web-based dastsets were used for data analysis. The web links to all the original data sources were listed as below: Three cDNA expression files GSE44077 (based on GPL6244[HuGene-1_0-st] Affymetrix Human Gene 1.0 ST Array. Web link: https://www.ncbi.nlm.nih.gov/geo/query/ acc.cgi?acc=GSE44077), GSE18842 (based on GPL570[HG-U133_Plus_2] Affymetrix Human Genome U133 Plus 2.0 Array. Web link: https://www.ncbi.nlm. nih.gov/geo/query/acc.cgi?acc=GSE18842) and GSE33532 (based on GPL570[HG-U133_Plus_2] Affymetrix Human Genome U133 Plus 2.0 Array.
Web link: https://www.ncbi.nlm.nih.gov/geo/query/acc.cgi?acc=GSE33532) were downloaded from Gene Expression Omnibus (GEO). And during the survival analysis of genes, 223 lung adenocarcinoma and 482 lung squamous cell carcinoma data were obtained from The Cancer Genome Atlas Program (TCGA) (Detailed in Supplementary Table 1 and Supplementary Table 2), meanwhile another analysis was conducted based on UALCAN (an interactive web resource for analyzing cancer transcriptome data. Web link: http://ualcan.path.uab.edu/analysis.html) provided lung adenocarcinoma and squamous cell carcinoma data. All data generated from the analysis process of this study are available from the corresponding author on reasonable request.

Ethics approval and consent to participate

Not applicable.

\section{Consent for publication}

Not applicable.

\section{Competing interests}

All of the authors approved the publication of the paper and declared no conflicts of interests. And as one of the corresponding author of the manuscript, Dr. Chen Wang works also as an associate editor of BMC Medical Genomics, we honestly declare that the whole process of manuscript reviewing was open, fair and impartial, absolutely no bias existed.

Received: 17 November 2019 Accepted: 4 August 2020

Published online: 14 August 2020

References

1. Torre LA, Bray F, Siegel RL, Ferlay J, Lortet-Tieulent J, Jemal A. Global cancer statistics, 2012. CA Cancer J Clin. 2015;65(2):87-108.

2. Siegel RL, Miller KD, Jemal A. Cancer statistics, 2017. CA Cancer J Clin. 2017; 67(1):7-30.

3. Wakelee H, Kelly K, Edelman MJ. 50 years of progress in the systemic therapy of non-small cell lung cancer. Am Soc Clin Oncol Educ Book. 2014; (34):177-89. https://doi.org/10.14694/EdBook_AM.2014.34.177.

4. Spiro SG, Silvestri GA. One hundred years of lung cancer. Am J Respir Crit Care Med. 2005;172(5):523-9.

5. Stella GM, Luisetti M, Pozzi E, Comoglio PM. Oncogenes in non-small-cell lung cancer: emerging connections and novel therapeutic dynamics. Lancet Respir Med. 2013;1(3):251-61.

6. Paez JG, Janne PA, Lee JC, et al. EGFR mutations in lung cancer: correlation with clinical response to gefitinib therapy. Science. 2004;304(5676):1497500.

7. Mitsudomi T, Yatabe Y. Mutations of the epidermal growth factor receptor gene and related genes as determinants of epidermal growth factor receptor tyrosine kinase inhibitors sensitivity in lung cancer. Cancer Sci. 2007:98(12):1817-24.

8. Tsao MS, Sakurada A, Cutz JC, et al. Erlotinib in lung cancer - molecular and clinical predictors of outcome. N Engl J Med. 2005;353(2):133-44.

9. Shaw AT, Felip E, Bauer TM, et al. Lorlatinib in non-small-cell lung cancer with ALK or ROS1 rearrangement: an international, multicentre, open-label, single-arm first-in-man phase 1 trial. Lancet Oncol. 2017;18(12):1590-9.

10. Soda M, Choi YL, Enomoto M, et al. Identification of the transforming EML4ALK fusion gene in non-small-cell lung cancer. Nature. 2007;448(7153):5616.

11. Croegaert K, Kolesar JM. Role of anaplastic lymphoma kinase inhibition in the treatment of non-small-cell lung cancer. Am J Health Syst Pharm. 2015; 72(17):1456-62.

12. Gerber DE, Minna JD. ALK inhibition for non-small cell lung cancer: from discovery to therapy in record time. Cancer Cell. 2010;18(6):548-51.

13. Botling J, Edlund $\mathrm{K}$, Lohr $\mathrm{M}$, et al. Biomarker discovery in non-small cell lung cancer: integrating gene expression profiling, meta-analysis, and tissue microarray validation. Clin Cancer Res. 2013;19(1):194-204.

14. Aibar S, Abaigar M, Campos-Laborie FJ, Sanchez-Santos JM, Hernandez-Rivas JM, De Las Rivas J. Identification of expression patterns in the progression of disease stages by integration of transcriptomic data. BMC Bioinformatics. 2016:17(Suppl 15):432

15. Kadara H, Fujimoto J, Yoo SY, et al. Transcriptomic architecture of the adjacent airway field cancerization in non-small cell lung cancer. J Natl Cancer Inst. 2014;106(3):dju004. 
16. Sanchez-Palencia A, Gomez-Morales M, Gomez-Capilla JA, et al. Gene expression profiling reveals novel biomarkers in nonsmall cell lung cancer Int J Cancer. 2011;129(2):355-64.

17. Meister M, Belousov A, EC X, et al. Intra-tumor Heterogeneity of Gene Expression Profiles in Early Stage Non-Small Cell Lung Cancer. J Bioinform Res Stud. 2014;1(1):1. https://www.researchgate.net/publication/265858060_ Intra-tumor_Heterogeneity_of_Gene_Expression_Profiles_in_Early_Stage_ Non-Small_Cell_Lung_Cancer.

18. Gene Expression Omnibus DataSets. https://www.ncbi.nlm.nih.gov/gds/ ?term. Accessed 4 May 2018.

19. GEO2R. https://www.ncbi.nlm.nih.gov/geo/geo2r/. Accessed 4 May 2018.

20. FunRich software. http://funrich.org/download. Accessed 6 April 2018.

21. Search Tool for the Retrieval of interacting Genes. https://string-db.org/. Accessed 5 May 2018.

22. Cytoscape3.6.0 software. http://www.softpedia.com/get/Science-CAD/ Cytoscape.shtml. Accessed 28 May 2018.

23. Kaplan Meier Plotter Survival analysis. http://kmplot.com/analysis/.Accessed 15 June2018.

24. National cancer institute https:// www. cancer. gov/ about-nci/ organization/ ccg/ research/ structural-genomics/tcga. Accessed 09 Sep 2019.

25. Gene Expression Profiling Interactive Analysis. http://gepia.cancer-pku.cn/. Accessed 8 May 2018.

26. Győrffy B, Surowiak P, Budczies J, Lánczky A. Online survival analysis software to assess the prognostic value of biomarkers using transcriptomic data in non-small-cell lung cancer. PloS one. 2013;8(12):e82241.

27. Human Protein Atlas. https://www.proteinatlas.org/. Accessed 10 Jun 2018.

28. Bendris N, Lemmers B, Blanchard JM. Cell cycle, cytoskeleton dynamics and beyond: the many functions of cyclins and CDK inhibitors. Cell Cycle. 2015; 14(12):1786-98.

29. Vermeulen K, Van Bockstaele DR, Berneman ZN. The cell cycle: a review of regulation, deregulation and therapeutic targets in cancer. Cell Prolif. 2003; 36(3):131-49.

30. Ingham M, Schwartz GK. Cell-cycle therapeutics come of age. J Clin Oncol. 2017:35(25):2949-59.

31. Kumar A, Sharma PR, Mondhe DM. Potential anticancer role of colchicinebased derivatives: an overview. Anti-Cancer Drugs. 2017;28(3):250-62.

32. Marzo-Mas A, Barbier P, Breuzard G, et al. Interactions of long-chain homologues of colchicine with tubulin. Eur J Med Chem. 2017;126:526-35.

33. Weaver BA. How Taxol/paclitaxel kills cancer cells. Mol Biol Cell. 2014;25(18): 2677-81.

34. Zasadil LM, Andersen KA, Yeum D, Rocque GB, et al. Cytotoxicity of paclitaxel in breast cancer is due to chromosome missegregation on multipolar spindles. Sci Transl Med. 2014;6(229):229ra243.

35. Xu B, Xu T, Liu H, Min Q, Wang S, Song Q. MiR-490-5p suppresses cell proliferation and invasion by targeting BUB1 in hepatocellular carcinoma cells. Pharmacology. 2017;100(5-6):269-82.

36. Xu B, Wu DP, Xie RT, Liu LG, Yan XB. Elevated NDC80 expression is associated with poor prognosis in osteosarcoma patients. Eur Rev Med Pharmacol Sci. 2017;21(9):2045-53.

37. Ju LL, Chen L, Li JH, et al. Effect of NDC80 in human hepatocellular carcinoma. World J Gastroenterol. 2017;23(20):3675-83.

38. Yan X, Huang L, Liu L, Qin H, Song Z. Nuclear division cycle 80 promotes malignant progression and predicts clinical outcome in colorectal cancer. Cancer Med. 2018;7(2):420-32.

39. Bieche I, Vacher S, Lallemand F, et al. Expression analysis of mitotic spindle checkpoint genes in breast carcinoma: role of NDC80/HEC1 in early breast tumorigenicity, and a two-gene signature for aneuploidy. Mol Cancer. 2011; 10:23

40. Vleugel M, Hoek TA, Tromer E, et al. Dissecting the roles of human BUB1 in the spindle assembly checkpoint. J Cell Sci. 2015;128(16):2975-82.

41. Abal M, Obrador-Hevia A, Janssen KP, et al. APC inactivation associates with abnormal mitosis completion and concomitant BUB1B/MAD2L1 upregulation. Gastroenterology. 2007;132(7):2448-58.

42. $\mathrm{Ko} \mathrm{YH}$, Roh JH, Son $\mathrm{Yl}$, et al. Expression of mitotic checkpoint proteins BUB1B and MAD2L1 in salivary duct carcinomas. J Oral Pathol Med. 2010; 39(4):349-55.

43. de Voer RM, Geurts van Kessel A, Weren RD, et al. Germline mutations in the spindle assembly checkpoint genes BUB1 and BUB3 are risk factors for colorectal cancer. Gastroenterology. 2013;145(3):544-7.
44. Tong H, Wang J, Chen H, Wang Z, Fan H, Ni Z. Transcriptomic analysis of gene expression profiles of stomach carcinoma reveal abnormal expression of mitotic components. Life Sci. 2017;170:41-9.

45. Martel-Frachet $\mathrm{V}$, Keramidas M, Nurisso A, et al. IPP51, a chalcone acting as a microtubule inhibitor with in vivo antitumor activity against bladder carcinoma. Oncotarget. 2015;6(16):14669-86.

46. Hasanov E, Chen G, Chowdhury P, et al. Ubiquitination and regulation of AURKA identifies a hypoxia-independent E3 ligase activity of VHL. Oncogene. 2017:36(24):3450-63.

47. Chen C, Song G, Xiang J, Zhang H, Zhao S, Zhan Y. AURKA promotes cancer metastasis by regulating epithelial-mesenchymal transition and cancer stem cell properties in hepatocellular carcinoma. Biochem Biophys Res Commun. 2017:486(2):514-20.

48. Puig-Butille JA, Vinyals A, Ferreres JR, et al. AURKA overexpression is driven by FOXM1 and MAPK/ERK activation in melanoma cells harboring BRAF or NRAS mutations: impact on melanoma prognosis and therapy. J Invest Dermatol. 2017;137(6):1297-310.

49. Song Z, Ge Y, Wang C, et al. Challenges and perspectives on the development of small-molecule EGFR inhibitors against T790M-mediated resistance in non-small-cell lung Cancer. J Med Chem. 2016;59(14):6580-94.

50. Chong CR, Janne PA. The quest to overcome resistance to EGFR-targeted therapies in cancer. Nat Med. 2013;19(11):1389-400.

51. Chen J, Lu H, Zhou W, et al. AURKA upregulation plays a role in fibroblastreduced gefitinib sensitivity in the NSCLC cell line HCC827. Oncol Rep. 2015; 33(4):1860-6.

52. Astsaturov I, Ratushny V, Sukhanova A, et al. Synthetic lethal screen of an EGFR-centered network to improve targeted therapies. Sci Signal. 2010; 3(140):ra67.

53. Kurup $S$, McAllister $B$, Liskova $P$, et al. Design, synthesis and biological activity of N (4)-phenylsubstituted-7H-pyrrolo [2,3-d]pyrimidin-4-amines as dual inhibitors of aurora kinase a and epidermal growth factor receptor kinase. J Enzyme Inhib Med Chem. 2018;33(1):74-84

54. Shah KN, Bhatt $\mathrm{R}$, Rotow J, et al. Aurora kinase A drives the evolution of resistance to third-generation EGFR inhibitors in lung cancer. Nat Med. 2019:25(1):111-8. https://doi.org/10.1038/s41591-018-0264-7.

\section{Publisher's Note}

Springer Nature remains neutral with regard to jurisdictional claims in published maps and institutional affiliations.
Ready to submit your research? Choose BMC and benefit from:

- fast, convenient online submission

- thorough peer review by experienced researchers in your field

- rapid publication on acceptance

- support for research data, including large and complex data types

- gold Open Access which fosters wider collaboration and increased citations

- maximum visibility for your research: over $100 \mathrm{M}$ website views per year

At $\mathrm{BMC}$, research is always in progress.

Learn more biomedcentral.com/submissions 